\title{
Effect of resuscitative endovascular balloon occlusion of the aorta in hemodynamically unstable patients with multiple severe torso trauma: a retrospective study
}

Hiroyuki Otsuka*, Toshiki Sato, Keiji Sakurai, Hiromichi Aoki, Takeshi Yamagiwa, Shinichi lizuka and Sadaki Inokuchi

\begin{abstract}
Background: Although resuscitative endovascular balloon occlusion of the aorta (REBOA) may be effective in trauma management, its effect in patients with severe multiple torso trauma remains unclear.

Methods: We performed a retrospective study to evaluate trauma management with REBOA in hemodynamically unstable patients with severe multiple trauma. Of 5899 severe trauma patients admitted to our hospital between January 2011 and January 2018, we selected 107 patients with severe torso trauma (Injury Severity Score > 16) who displayed persistent hypotension [ $\geq 2$ systolic blood pressure (SBP) values $\leq 90 \mathrm{mmHg}$ ] regardless of primary resuscitation. Patients were divided into two groups: trauma management with REBOA $(n=15)$ and without REBOA $(n=92)$. The primary endpoint was the effectiveness of trauma management with REBOA with respect to inhospital mortality. Secondary endpoints included time from arrival to the start of hemostasis. Multivariable logistic regression analysis, adjusted for clinically important variables, was performed to evaluate clinical outcomes.

Results: Trauma management with REBOA was significantly associated with decreased mortality (adjusted odds ratio of survival, $7.430 ; 95 \%$ confidence interval, 1.081-51.062; $p=0.041$ ). The median time (interquartile range) from admission to initiation of hemostasis was not significantly different between the two groups [with REBOA 53.0 (40.0-80.3) min vs. without REBOA 57.0 (35.0-100.0) min ]. The time from arrival to the start of balloon occlusion was $55.7 \pm 34.2 \mathrm{~min}$. SBP before insertion of REBOA was $48.2 \pm 10.5 \mathrm{mmHg}$. Total balloon occlusion time was $32.5 \pm 18.2 \mathrm{~min}$.
\end{abstract}

Conclusions: The use of REBOA without a delay in initiating resuscitative hemostasis may improve the outcomes in patients with multiple severe torso trauma. However, optimal use may be essential for success.

Keywords: Resuscitative endovascular balloon occlusion of the aorta, Multiple lethal trauma, Resuscitation, Trauma management

\section{Background}

Recently, new concepts and technologies such as damage-control strategies, whole-body computed tomography $(\mathrm{CT})$, endovascular treatment, and hybrid operating rooms have been developed for the treatment of trauma patients [1-7]. Similarly, resuscitative endovascular balloon occlusion of the aorta (REBOA) has been widely used in

\footnotetext{
* Correspondence: hirootsu@is.icc.u-tokai.ac.jp

Department of Emergency and Critical Care Medicine, Tokai University

School of Medicine, 143 Shimokasuya, Isehara city, Kanagawa Prefecture 259-1193, Japan
}

the management of hemorrhagic shock [8]. Its effectiveness for trauma patients has been evaluated in many large-scale studies [9-13]; however, the evidence base is weak and clear indications are lacking. Furthermore, although the time and place of balloon insertion, zone of balloon inflation, and inflation cutoff time are very important, they are heterogeneous factors [11, 14-18]. In addition, while it has been conceivable that REBOA may be effective in patients with severe trauma when integrated with surgery or interventional radiology (IVR) without delay [9], it remains 
challenging to successfully perform REBOA in patients with severe multiple torso traumas.

The aim of this study was to evaluate our trauma management with REBOA in hemodynamically unstable patients with multiple severe trauma.

\section{Methods}

\section{Study design and selection criteria}

A total of 5899 severe trauma patients were admitted to our hospital between January 2011 and January 2018. Among them, we selected 107 patients with severe torso trauma [Injury Severity Score (ISS) >16] who displayed persistent hypotension [ $\geq 2$ systolic blood pressure (SBP) values $\leq$ $90 \mathrm{mmHg}$ ] regardless of primary resuscitation (airway management, massive transfusion, and/or reversal of obstructive shock) without cardiopulmonary arrest on admission. The patients were divided into two groups: trauma management with REBOA or without REBOA (Fig. 1). The with REBOA group indicated REBOA used primarily, and not secondarily, after open aortic cross-clamping via resuscitative thoracotomy as part of the cardiopulmonary resuscitation procedure. We retrospectively evaluated the characteristics of the patients, hematological tests at the time of admission, severity of trauma, treatment-related characteristics, and outcomes. We defined the primary endpoint as the effectiveness of REBOA for in-hospital mortality. In addition, we set the following secondary endpoints to evaluate the effectiveness of REBOA: pre-hemostasis CT scan performance ratio, REBOA performance ratio before $\mathrm{CT}$, ratio of patients who underwent hemostasis, total amount of red blood cells (RBCs) and fresh frozen plasma (FFP) transfused, ratio of patients who underwent surgery as primary hemostasis among those who underwent hemostasis, time course from arrival to the start of surgery/IVR, pre-hemostasis-administrated $\mathrm{RBCs}$ and FFP, and REBOA-related characteristics.

\section{REBOA procedure}

The use of REBOA at our institution was started between 20 and 25 years ago. The decision to use REBOA and performing the procedure was at the discretion of the emergency physicians (EPs) or trauma surgeons. All EPs in our hospital have completed a 3-month course of radiology training (mainly vascular IVR). We have used REBOA in patients with severe multiple trauma as follows: the use of REBOA should never result in any delay in the initiation of resuscitative surgery/IVR; REBOA is used to prevent cardiac arrest and not to improve the shock state in patients with severe hemorrhagic shock. However, we do not make any guidelines for the use of REBOA. REBOA has been used under simply primary doctor judgment. In our center, most trauma patients who deteriorated into a state of severe shock have received an insertion of 4-French sheath into the common femoral artery, for the continuous measurement of arterial pressure or performing IVR irrespective of whether REBOA was used or not. Femoral access was obtained through anatomic landmarks using sonography without a surgical incision. REBOA was performed by inserting a 12-French or 7-French sheath set in the common femoral artery. Through the sheath, a balloon catheter was blindly inserted and initially inflated in the aortic zone I [19], located between the left subclavian artery and the celiac artery.

\section{Trauma management}

Our institution is a tertiary referral hospital that includes a specialized department in trauma management and intensive care. Moreover, the CT scan, angiography suite (AS), and operating room (OR) are part of the emergency department (ED) in our hospital and available for use at all hours. All trauma surgeons in our hospital have been trained in emergency medicine and general

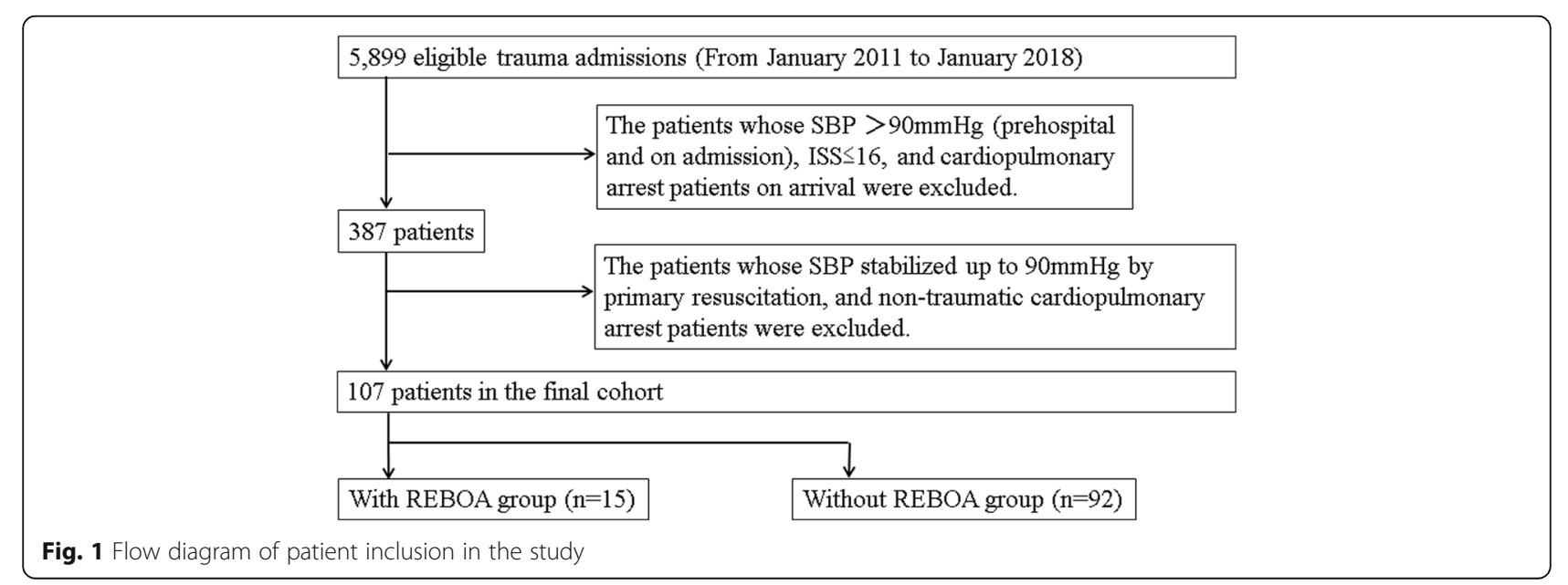


surgery and are also trained in cardiovascular surgery and IVR. The decision to perform surgery or IVR was made at the discretion of EPs or the trauma surgeons in the ED.

\section{Data collection}

The ED variables [Glasgow Coma Scale (GCS), respiratory rate (RR), SBP, body temperature (BT), pulse rate, $\mathrm{pH}$, base excess, lactate value, D-dimer, and prothrombin time-international normalized ratio] were recorded as the initial set of vital signs and laboratory tests. Revised Trauma Score (RTS), ISS, and probability of survival calculated using the Trauma and Injury Severity Score (TRISS-Ps) were used for analyzing patient characteristics and severity.

\section{Statistical analysis}

Statistical analyses were performed using SPSS software (Windows version 22.0; SPSS Inc., Chicago, IL, USA). For the primary endpoint, multivariable logistic regression analysis was performed to evaluate the effectiveness of REBOA before cardiopulmonary arrest after adjusting for age, RTS, ISS, pre-hemostasis-administrated RBCs, and the logarithm of time from admission to the start of hemostasis. For patients' baseline characteristics and secondary endpoints, categorical variables were compared using the $\chi^{2}$ test or Fisher's exact test, and continuous variables were analyzed using the Student's $t$ test or the Mann-Whitney $U$ test. The values are presented as either the mean \pm standard deviation or the median (interquartile range $[\mathrm{IQR}] 25-75)$. Statistical significance was defined as a $p$ value of less than 0.05 or was assessed using $95 \%$ confidence intervals (CI).

This study was approved by the institutional review board for clinical research, Tokai University (approval no.: 17R-344).

\section{Results}

Fifteen patients were included in the with REBOA group, and 92 patients were included in the without REBOA group. Table 1 summarizes the patients' baseline characteristics. There were no significant differences between the two groups.

The primary endpoint is presented in Table 2. Although the 24-h and in-hospital mortality were not significantly different between the two groups when compared using the $\chi^{2}$ test, REBOA was associated with a significant decrease in the in-hospital mortality when adjusted for age, RTS, ISS, pre-hemostasis-administrated RBCs, and the logarithm of time from admission to initiating surgery/IVR, using the multivariable logistic regression analysis. Adjusted odds ratio (OR) of survival was 7.430 , and $95 \%$ CI was $1.081-51.062$ $(p=0.041)$.
The secondary endpoints are presented in Tables 3 and 4. The amount of pre-hemostasis-administrated RBCs in the with REBOA group was higher than that in the without REBOA group when compared using the Mann-Whitney $U$ test. However, there were no significant differences in any of the other parameters between both groups. Patients who were bleeding due to multiple injuries such as multiple facial bone fractures, skull base fractures with intracranial hemorrhage, mediastinal hematoma, chest wall hematoma, retroperitoneal hematoma, abdominal wall hematoma, or multiple extremities bone fractures, all of which were difficult to diagnose without $\mathrm{CT}$, were not eligible for the hemostasis. These patients went into cardiac arrest before the hemostasis could be performed.

The REBOA-related characteristics analyzed in this study are shown in Table 5 . The time from admission to the start of balloon occlusion was $55.7 \pm 34.2 \mathrm{~min}$. From the REBOA group, 12 (80\%) patients underwent CT before hemostasis. Among them, 6 (50\%) patients underwent REBOA prior to CT. Hemostasis was initiated in 5 patients before they could receive REBOA. SBP just before the inflation of REBOA was $48.2 \pm 10.5 \mathrm{mmHg}$. Total time for balloon occlusion was $32.5 \pm 18.2 \mathrm{~min}$. Two patients received both the intermittent and partial methods. A rest of 1-2 min was allowed after every $10 \mathrm{~min}$ of occlusion. Prior to removal, the volume of the inflated balloon was gradually reduced. The total occlusion time of the $2 \mathrm{pa}-$ tients were 50 and $60 \mathrm{~min}$, respectively.

REBOA-related complications occurred in two patients without severe atherosclerotic changes. One middle-aged male patient, for whom the duration of balloon occlusion was $61 \mathrm{~min}$, accompanied with arterial dissection of the right common iliac artery, left limb ischemia that required below-knee amputation, and acute kidney injury (AKI) that required hemodialysis. The time from admission to the initiation of laparotomy was 40 min without CT scan, and the time from admission to the inflation of the balloon (12-Fr REBOA set) was $50 \mathrm{~min}$. The systolic blood pressure just before the balloon occlusion was $48 \mathrm{mmHg}$, the RTS was 6.085, and the ISS was 50. To prevent cardiac arrest, the balloon should not be deflated until the final stage of hemostasis. Another patient only required the dissection of the common iliac artery using a 12-French set. The dissections in both patients were conservatively treated, and their condition improved. AKI also improved with time. Eventually, both patients were able to resume a normal life.

\section{Discussion}

The main finding of this study was that the use of REBOA was associated with reduced in-hospital mortality in patients with multiple severe torso trauma. Despite the use of REBOA in these patients, we were able to 
Table 1 Characteristics and severity

\begin{tabular}{|c|c|c|c|}
\hline & With REBOA $(n=15)$ & Without REBOA $(n=92)$ & $p$ \\
\hline Age, years & $52.7 \pm 19.8$ & $52.1 \pm 21.0$ & 0.67 \\
\hline Male gender (\%) & $11(73.3)$ & $59(64.1)$ & 0.487 \\
\hline \multicolumn{4}{|l|}{ Mechanism of injury } \\
\hline Motor vehicle accident & 9 & 41 & \multirow[t]{6}{*}{0.977} \\
\hline Fall from a height & 5 & 34 & \\
\hline Stabbing & 0 & 11 & \\
\hline Compression & 1 & 4 & \\
\hline Gunshot & 0 & 1 & \\
\hline Violence & 0 & 1 & \\
\hline \multicolumn{4}{|l|}{ Vital signs on admission } \\
\hline GCS total score & $11.0(3.0-14.0)$ & $9.0(4.25-14.0)$ & 0.83 \\
\hline GCS < $9(\%)$ & $6(40.0)$ & $45(48.9)$ & 0.522 \\
\hline$R R$, per min & $24.0(24.0-30.0)$ & $24.0(18.0-30.0)$ & 0.643 \\
\hline $\mathrm{SBP}, \mathrm{mmHg}$ & $60.0(52.0-90.0)$ & $71.0(56.5-84.5)$ & 0.474 \\
\hline BT, Celsius & $36.0(35.0-36.8)$ & $36.0(35.4-36.7)$ & 0.804 \\
\hline Pulse rate, beats per min & $107.2 \pm 24.4$ & $108.7 \pm 28.8$ & 0.33 \\
\hline \multicolumn{4}{|l|}{ Laboratory evaluation } \\
\hline $\mathrm{pH}$ & $7.27(7.13-7.44)$ & $7.26(7.08-7.35)$ & 0.237 \\
\hline Base excess, mmol/L & $-9.7(-14.4$ to -3.2$)$ & $-9.7(-18.3$ to -5.7$)$ & 0.353 \\
\hline Lactate, mg/dL & $73.0(36.0-91.0)$ & $56.5(36.0-100.0)$ & 0.711 \\
\hline D-dimer, $\mu \mathrm{g} / \mathrm{mL}$ & $82.0(27.6-117.7)$ & 43.5 (15.9-99.9) & 0.338 \\
\hline PT-INR & $1.2(1.0-1.4)$ & $1.2(1.0-1.4)$ & 0.859 \\
\hline \multicolumn{4}{|l|}{ Trauma Score } \\
\hline RTS & $5.6(2.6-6.6)$ & $5.5(3.5-6.6)$ & 0.993 \\
\hline ISS & $50.0(41.0-66.0)$ & $41.0(29.0-50.0)$ & 0.097 \\
\hline TRISS-Ps, \% & $43.3(1.4-84.7)$ & $36.9(7.0-73.8)$ & 0.76 \\
\hline \multicolumn{4}{|l|}{ Treatment outcome } \\
\hline 24-h mortality (\%) & $3(20.0)$ & $33(35.9)$ & 0.228 \\
\hline In-hospital mortality (\%) & $6(40.0)$ & $52(56.5)$ & 0.234 \\
\hline
\end{tabular}

REBOA resuscitative endovascular balloon occlusion of the aorta, GCS Glasgow Coma Scale, $R R$ respiratory rate, SBP systolic blood pressure, $B T$ body temperature, PT-INR prothrombin time-international normalized ratio, RTS Revised Trauma Score, ISS Injury Severity Score, TRISS-PS Probability of survival calculated by the Trauma and Injury Severity Score

initiate surgery/IVR early in the with REBOA group than in the without REBOA group.

In this study, we used age, RTS, ISS, pre-hemostasis-administrated RBCs, and time from admission to the start of hemostasis as confounding variables. Age, RTS, and ISS were selected to exclude the influence of aging as well as physiological and anatomical differences [20, 21]. Furthermore, we added pre-hemostasis-administrated $\mathrm{RBCs}$ and time from

Table 2 Primary endpoint

\begin{tabular}{lll}
\hline Variable & Adjusted odds ratio of survival $(95 \% \mathrm{Cl})$ & $p$-value \\
\hline REBOA & $7.430(1.081-51.062)$ & 0.041 \\
\hline
\end{tabular}

$R E B O A$ resuscitative endovascular balloon occlusion of the aorta, $\mathrm{Cl}$ confidence interval admission to the start of hemostasis, which are the essentials for hemorrhage control in severely injured patients [22]. In addition, the results of time from admission to the start of hemostasis were skewed; therefore, we used the values for which logarithmic transformation was conducted. TRISS-Ps, lactate, base excess, and D-dimer values were used to evaluate the level of trauma severity between the two groups [23-25].

Inoue et al. [9] conducted a subgroup analysis of door-to-primary surgery time of $<60 \mathrm{~min}$ vs. $\geq 60 \mathrm{~min}$ and observed significant interactions, which may indicate that surgery time of $\geq 60$ min could worsen in-hospital mortality. A delay in definitive hemostasis after REBOA may be one of the drawbacks that resulted in high mortality. Our analysis demonstrated that the 
Table 3 Pre-hemostasis CT scan and hemostasis performance ratio and total amount of blood transfusions

\begin{tabular}{llll}
\hline & With REBOA $(n=15)$ & Without REBOA $(n=92)$ & $p$ \\
\hline Pre-hemostasis CT scan performance ratio (\%) & $12(80.0)$ & $60(65.2)$ & $81(88.0)$ \\
The ratio of patients who underwent hemostasis (\%) & $14(93.3)$ & & 0.258 \\
Total amount of blood transfusions, units & & $16.0(6.0-25.0)$ & 0.643 \\
Red blood cells & $16.0(14.0-20.0)$ & $8.0(4.0-18.0)$ & 0.323 \\
$\quad$ Fresh frozen plasma & $14.0(6.0-20.0)$ &
\end{tabular}

time from admission to the start of surgery/IVR with REBOA was approximately $60 \mathrm{~min}$, while the time from admission to deflating the balloon was approximately < $90 \mathrm{~min}$. These results suggested that hemorrhage could be controlled within $90 \mathrm{~min}$ with surgery/IVR/REBOA in patients with multiple lethal torso trauma. Taken together, the most important factor required to successfully perform REBOA in patients with multiple severe trauma may be the rapid achievement of complete hemostasis. In other words, the use of REBOA should not be a cause of delay in hemostasis.

Our usage of REBOA had the following unique features: shorter occlusion time despite longer time from arrival to the start of balloon occlusion and lower SBP just before REBOA insertion compared with other instances in current literature $[11,13,14]$; the ratio of the patients who underwent REBOA was, low and resuscitative hemostasis had been initiated in five patients before the insertion of REBOA. We had used REBOA based on permissive hypotension [1-4]. Although cardiac arrest should be avoided, we considered the possible harmful effects of not just the long aortic occlusion time but also the unnecessary rising of central SBP due to early use of REBOA, especially in patients with multiple injuries. Hence, unnecessary use of REBOA should be avoided. REBOA might be used to increase afterload with redistribution of blood flow and prevent cardiac arrest, rather than perform hemorrhage control of the distal arteries. The result showed that REBOA might exert effects that can help preserve brain and coronary blood flow while improving outcomes. However, the optimal patient selection is difficult, and the other effects of REBOA remain unclear. Further investigations are needed regarding selection guidelines.
Another notable drawback is REBOA-related complications. Despite technological advancements, REBOA is associated with significant risks due to complications of vascular access and reperfusion ischemia [26, 27]. The serious complication of lower limb ischemia, which may lead to amputation, occurred with high frequency $(3 / 24$ patients) in a previous study [28]. In our study, lower limb ischemia, which also required amputation, occurred in 1 of 15 patients. Moreover, there were some REBOA-related complications. Although the exact reasons for the occurrence of the severe complications observed in this study were unclear, we believe that the large size and rigidity of the 12-Fr REBOA and the long occlusion time in patients whose arteries might be in a state of vasospasm could explain such complications. To save the patient's life, some REBOA-related complications may even be inevitable, although all attempts should be made to avoid any adverse sequelae caused by REBOA-related complications. Some studies reported that small introducer sheaths for REBOA may be associated with fewer complications [27, 29] and that ultrasound should be optimized for REBOA [30]. Moreover, partial or intermittent REBOA should be considered in some cases [31, 32]. However, their effect remains unclear. Thus, prevention of REBOA-related morbidity is also important for successful trauma management with REBOA; however, we could not evaluate any possible harmful effects on mortality.

Statistically, this study may have some type 2 errors owing to a low-power analysis with the small sample size. However, our results suggest that there was non-inferiority at least with the REBOA group compared with the without-REBOA group. Therefore, we believe

Table 4 Surgery/IVR-related characteristics and total amount of preoperative blood transfusions in the patients with surgery/IVR

\begin{tabular}{llll}
\hline & With REBOA $(n=14)$ & Without REBOA $(n=81)$ & $p$ \\
\hline Patients who underwent surgery for PH (\%) & $8(57.1)$ & $38(46.9)$ & $57.0(35.0-100.0)$ \\
Time to initiation PH, min & $53.0(40.0-80.3)$ & & 0.643 \\
Preoperative blood transfusions, $\mathrm{mL}$ & & $560.0(280.0-1120.0)$ & 0.908 \\
Red blood cells & $840.0(560.0-1120.0)$ & $0(0-240.0)$ & 0.104 \\
$\quad$ Fresh frozen plasma & $120.0(0.0-300.0)$ &
\end{tabular}


Table 5 REBOA related-characteristics

\begin{tabular}{lc}
\hline & With REBOA (n=15) \\
\hline Time from admission to start balloon occlusion, min & $55.7 \pm 34.2$ \\
The number of patients who underwent REBOA prior to CT (\%) & $6(40.0)$ \\
The number of patients who started hemostasis before REBOA (\%) & $5(33.3)$ \\
SBP just before inflation of the REBOA, mmHg & $48.2 \pm 10.5$ \\
Total length of balloon occlusion time, min & $32.5 \pm 18.2$ \\
The number of patients who received both intermittent and partial methods (\%) & $2(13.3)$ \\
The morbidity of REBOA (\%) & $2(13.3)$ \\
Arterial dissection (\%) & $2(13.3)$ \\
Limb ischemia required below-the-knee amputation (\%) & $1(6.7)$
\end{tabular}

REBOA resuscitative endovascular balloon occlusion of the aorta, $C T$ computed tomography, SBP systolic blood pressure, $H D$ hemodialysis

that these results may be of value in performing further prospective and multicenter studies.

There were several limitations to this study. Our study was conducted at a single center with a small sample size and retrospective study design. Our results were obtained using careful patient selection; however, the potential number of patients could have been higher. Therefore, there may be an obvious selection bias. Moreover, cases of severe trauma referred to our center were highly specific, complex, and had low interdisciplinarity. Medical equipment and techniques have progressed substantially. More cases should be assessed for investigation in future studies.

\section{Conclusions}

The use of REBOA without a delay in initiating resuscitative hemostasis may improve the outcomes in patients with multiple injuries associated with severe trauma. Optimal usage of REBOA may be beneficial in preventing cardiac arrest and preserving brain and coronary blood flow without harmful effects. Further studies to assess optimal usage criteria are needed.

\section{Abbreviations}

AKI: Acute kidney injury; AS: Angiography suite; Cl: Confidence interval; $\mathrm{CT}$ : Computed tomography; ED: Emergency department; EPs: Emergency physicians; FFP: Fresh frozen plasma; ISS: Injury Severity Score;

IVR: Interventional radiology; OR: Odds ratio; OR: Operating room; RBCs: Red blood cells; REBOA: Resuscitative endovascular balloon occlusion of the aorta; RTS: Revised trauma score; SBP: Systolic blood pressure

\section{Acknowledgments}

None.

\section{Funding}

This study did not receive any funding.

\section{Availability of data and materials}

Not applicable

\section{Authors' contributions}

$\mathrm{HO}$ and SIn had full access to all the data in the study and take responsibility for the integrity and accuracy of the data. HO, TS, SK, HA, TY, and Sli contributed to the creation of the strategy for resuscitation using REBOA in practice. The final version was read and approved by all authors.

\section{Ethics approval and consent to participate}

This study was approved by the institutional review board for clinical research, Tokai University approval no.: 17R-344.

Consent for publication

Not applicable

\section{Competing interests}

The authors declare that they have no competing interests.

\section{Publisher's Note}

Springer Nature remains neutral with regard to jurisdictional claims in published maps and institutional affiliations.

Received: 17 May 2018 Accepted: 10 October 2018

Published online: 25 October 2018

References

1. Rotondo MF, Schwab CW, McGonigal MD, Phillips GR 3rd, Fruchterman TM, Kauder DR, et al. 'Damage control': an approach for improved survival in exsanguinating penetrating abdominal injury. J Trauma. 1993;35:375-82 discussion 382-3.

2. Moore EE, Burch JM, Franciose RJ, Offner PJ, Biffl WL. Staged physiologic restoration and damage control surgery. World J Surg. 1998;22:1184-90 discussion 1190-1.

3. Shapiro MB, Jenkins DH, Schwab CW, Rotondo MF. Damage control: collective review. J Trauma. 2000:49:969-78.

4. Stahel PF, Smith WR, Moore EE. Current trends in resuscitation strategy for the multiply injured patient. Injury. 2009:40:S27-35.

5. Leidner B, Beckman MO. Standardized whole-body computed tomography as a screening tool in blunt multitrauma patients. Emerg Radiol. 2001;8:20-8.

6. Ball CG, Kirkpatrick AW, D'Amours SK. The RAPTOR: resuscitation with angiography, percutaneous techniques and operative repair: transforming discipline of trauma surgery. Can J Surg. 2011;54:E3-4.

7. Kinoshita T, Yamakawa K, Matsuda H, Yoshikawa Y, Wada D, Hamasaki T, et al. The survival benefit of a novel trauma workflow that includes immediate whole-body computed tomography, surgery, and interventional radiology, all in one trauma resuscitation room: a retrospective historical control study. Ann Surg. 2017. https://doi.org/10.1097/SLA. 0000000000002527.

8. Morrison JJ, Galgon RE, Jansen JO, Cannon JW, Rasmussen TE, Eliason JL. A systematic review of the use of resuscitative endovascular balloon occlusion of the aorta in the management of hemorrhagic shock. J Trauma Acute Care Surg. 2016;80:324-34.

9. Inoue J, Shiraishi A, Yoshiyuki A, Haruta K, Matsui H, Otomo Y. Resuscitative endovascular balloon occlusion of the aorta might be dangerous in 
patients with severe torso trauma: a propensity score analysis. J Trauma Acute Care Surg. 2016;80:559-66 discussion 566-7.

10. Moore LJ, Martin CD, Harvin JA, Wade CE, Holcomb JB. Resuscitative endovascular balloon occlusion of the aorta for control of noncompressible truncal hemorrhage in the abdomen and pelvis. Am J Surg. 2016;212:1222-30.

11. Gamberini E, Coccolini F, Tamagnini B, Martino C, Albarello V, Benni M, et al. Resuscitative endovascular balloon occlusion of the aorta in trauma: a systematic review of the literature. World J Emerg Surg. 2017;12:42.

12. Norii T, Crandall C, Terasaka Y. Survival of severe blunt trauma patients treated with resuscitative endovascular balloon occlusion of the aorta compared with propensity score-adjusted untreated patients. J Trauma Acute Care Surg. 2015;78:721-8.

13. Brenner M, Teeter W, Hoehn M, Pasley J, Hu P, Yang S, et al. Use of resuscitative endovascular balloon occlusion of the aorta for proximal aortic control in patients with severe hemorrhage and arrest. JAMA Surg. 2018;153:130-5.

14. Pieper A, Thony F, Brun J, Rodière M, Boussat B, Arvieux C, et al. Resuscitative endovascular balloon occlusion of the aorta for pelvic blunt trauma and life-threatening hemorrhage: a 20-year experience in a level I trauma center. J Trauma Acute Care Surg. 2018;84:449-53.

15. DuBose JJ. How I do it: partial resuscitative endovascular balloon occlusion of the aorta (P-REBOA). J Trauma Acute Care Surg. 2017;83:197-9.

16. Biffl WL, Fox CJ, Moore EE. The role of REBOA in the control of exsanguinating torso hemorrhage. J Trauma Acute Care Surg. 2015;78:1054-8.

17. Johnson MA, Davidson AJ, Russo RM, Ferencz SE, Gotlib O, Rasmussen TE, et al. Small changes, big effects: the hemodynamics of partial and complete aortic occlusion to inform next generation resuscitation techniques and technologies. J Trauma Acute Care Surg. 2017:82:1106-11.

18. Romagnoli A, Teeter W, Pasley J, Hu P, Hoehn M, Stein D, et al. Time to aortic occlusion: it's all about access. J Trauma Acute Care Surg. 2017;83: $1161-4$.

19. Martinelli T, Thony F, Decléty P, Sengel C, Broux C, Tonetti J, et al. Intraaortic balloon occlusion to salvage patients with life-threatening hemorrhagic shocks from pelvic fractures. J Trauma. 2010;68:942-8.

20. Champion HR, Sacco WJ, Copes WS, Gann DS, Gennarelli TA, Flanagan ME. A revision of the Trauma Score. J Trauma. 1989:29:623-9.

21. Baker SP, O'Neill B, Haddon W Jr, Long WB. The injury severity score: a method for describing patients with multiple injuries and evaluating emergency care. J Trauma. 1974;14:187-96.

22. Gruen RL, Brohi K, Schreiber M, Balogh ZJ, Pitt V, Narayan M, et al. Haemorrhage control in severely injured patients. Lancet. 2012;380:1099-108.

23. de Munter L, Polinder S, Lansink KW, Cnossen MC, Steyerberg EW. Mortality prediction models in the general trauma population: a systematic review. Injury. 2017;48:221-9.

24. Ibrahim I, Chor WP, Chue KM, Tan CS, Tan HL, Siddiqui FJ, et al. Is arterial base deficit still a useful prognostic marker in trauma? A systematic review. Am J Emerg Med. 2016;34:626-35.

25. Umebachi R, Taira T, Wakai S, Aoki H, Otsuka H, Nakagawa Y, et al. Measurement of blood lactate, D-dimer, and activated prothrombin time improves prediction of in-hospital mortality in adults blunt trauma. Am J Emerg Med. 2018;36:370-5.

26. Davidson AJ, Russo RM, Reva VA, Brenner ML, Moore LJ, Ball C, et al. The pitfalls of resuscitative endovascular balloon occlusion of the aorta: risk factors and mitigation strategies. J Trauma Acute Care Surg. 2018; 84:192-202.

27. Taylor JR 3rd, Harvin JA, Martin C, Holcomb JB, Moore LJ. Vascular complications from resuscitative endovascular balloon occlusion of the aorta: life over limb? J Trauma Acute Care Surg. 2017;83:S120-3.

28. Saito N, Matsumoto H, Yagi T, Hara Y, Hayashida K, Motomura T, et al. Evaluation of the safety and feasibility of resuscitative endovascular balloon occlusion of the aorta. J Trauma Acute Care Surg. 2015;78:897-903 discussion 904.

29. Teeter WA, Matsumoto J, Idoguchi K, Kon Y, Orita T, Funabiki T, et al. Smaller introducer sheaths for REBOA may be associated with fewer complications. J Trauma Acute Care Surg. 2016;81:1039-45.

30. Bogert JN, Patel BM, Johnson DJ. Ultrasound optimization for resuscitative endovascular balloon occlusion of the aorta. J Trauma Acute Care Surg. 2017;82(1):204-7.

31. Kuckelman J, Barron M, Moe D, Derickson M, Phillips C, Kononchik J, et al. Extending the golden hour for zone 1 REBOA: improved survival and reperfusion injury with intermittent versus continuous REBOA in a porcine severe truncal hemorrhage model. J Trauma Acute Care Surg. 2018. https:// doi.org/10.1097/TA.0000000000001964

32. Russo RM, Williams TK, Grayson JK, Lamb CM, Cannon JW, Clement NF. Extending the golden hour: partial resuscitative endovascular balloon occlusion of the aorta in a highly lethal swine liver injury model. J Trauma Acute Care Surg. 2016;80:372-8 discussion 378-80.

\section{Ready to submit your research? Choose BMC and benefit from:}

- fast, convenient online submission

- thorough peer review by experienced researchers in your field

- rapid publication on acceptance

- support for research data, including large and complex data types

- gold Open Access which fosters wider collaboration and increased citations

- maximum visibility for your research: over $100 \mathrm{M}$ website views per year

At BMC, research is always in progress.

Learn more biomedcentral.com/submissions 